Article

\title{
Evolution of Fretting Wear Behaviors and Mechanisms of 20CrMnTi Steel after Carburizing
}

\author{
Jinchi Tang ${ }^{1,2}$, Xiongfeng $\mathrm{Hu}^{3}$, Fuqiang Lai ${ }^{3,4, *}$, Xiaolong Guo ${ }^{1,2}$, Shengguan $\mathrm{Qu}^{3} \mathbb{C}$, \\ Ruiliang $\mathrm{He}^{3}$, Shunshun Qin ${ }^{1,2}$ and Jianwen $\mathrm{Li}^{1,2}$ \\ 1 State Key Laboratory of Engine Reliability, Weifang 261061, China; tangj@@weichai.com (J.T.); \\ guoxl@weichai.com (X.G.); qinss@weichai.com (S.Q.); lijianw@weichai.com (J.L.) \\ 2 Weichai Power Co. Ltd., Weifang 261061, China \\ 3 School of Mechanical and Automotive Engineering, South China University of Technology, \\ Guangzhou 510641, China; huxiongfeng1992@163.com (X.H.); qusg@scut.edu.cn (S.Q.); \\ ruilianghe@126.com (R.H.) \\ 4 School of Mechanical Engineering and Automation, Qishan Campus, Fuzhou University, Fuzhou 350108, \\ China \\ * Correspondence: lfq0623@163.com; Tel.: +86-1881-411-2792
}

Received: 27 December 2019; Accepted: 23 January 2020; Published: 25 January 2020

\begin{abstract}
In this paper, the fretting wear properties of 20CrMnTi steel, a common material for a rocker bracket, was discussed for the first time after it was suffered carburizing treatment. Subsequently, the fretting wear behaviors of virgin, quenched, and carburized states were studied. The effect of loads (corresponding to different engine power output) and reciprocating frequencies (corresponding to different engine speed) on wear behaviors and mechanisms of carburized specimen were further discussed. The results showed that the coefficient of friction (CoF) and wear volume loss (WVL) of the carburized specimens were significantly lower than that of virgin and quenched states. During the wear test, the surface CoF decreased gradually with the increase of applied load, while the linear correlation trend was not observed with the increase of fretting frequency as it showed an increase first and then a decrease. It was observed that the WVL increased gradually with the increase of load and frequency. With an increase of the load, the wear mechanism gradually deteriorated from the initial adhesive wear to the mixed wear mechanism. When the load was high, the oxidative wear became more severe. However, no significant effect of frequency was observed on the wear mechanism.
\end{abstract}

Keywords: valvetrain; carburizing; fretting wear; 20CrMnTi steel

\section{Introduction}

A valvetrain is a mechanism assembly that controls the intake/exhaust of an internal combustion engine, which has a direct influence on the driving stability [1]. Recent studies have shown that more than $40 \%$ of total energy loss is caused by friction in the engine system [2]. Approximately one-third of this estimated energy loss of engine has been consumed by the valvetrain [3]. Fretting wear refers to the wear behavior caused by small reciprocating between contact components, which is almost inevitable in spite of engine designers' attempts to improve the design or use better lubricants. It is well known that most failure forms of a component are catastrophic to the engine, which not only significantly reduces the performance of fuel combustion, but also brings a high reciprocating and noise for mechanisms [4]. Therefore, a better identification of mechanisms of fretting wear caused by friction between components has become one of the necessary means to enhance engine performance, prolong its service life and improve fuel efficiency.

Rocker arm-rocker bracket tribo-pair has the characteristics of close contact and a short sliding distance, which is one of the most easily worn tribo-pairs in the valvetrain, as shown in Figure 1. 
The research of $\mathrm{Xu}$ et al. [5] intuitively presented the fatigue fracture behavior caused by rocker arm-rocker bracket tribo-pair wear, and found that the friction and wear behavior of rocker arm-rocker bracket interface is mainly manifested as composite fretting wear under the co-action of load and reciprocating generated during engine operation and it is often neglected artificially. Once the wear reaches a sufficient level, it will seriously influence the transmission of torque and make the intake/exhaust valves work slowly, thus reducing the engine efficiency and service life of driving components, and even resulting in the fracture of the rocker bracket.

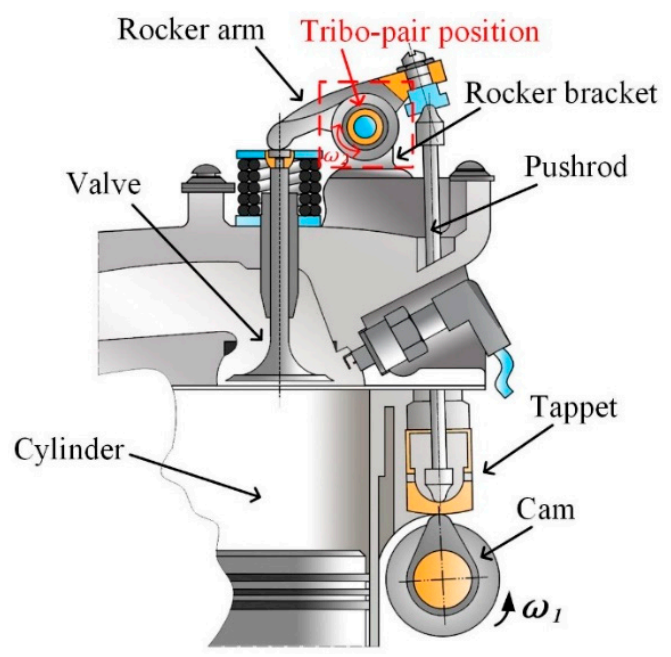

Figure 1. Position of valve rocker-valve rocker bracket tribo-pair.

The improvement of surface performance is the primary way to against the fatigue and wear problems of the components. Quenching is a final heat treatment process widely accepted as part of valve rocker and valve rocker bracket, which can obtain martensite microstructure with excellent abrasion performance. However, with the gradual increase of the engine power density and cylinder combustion pressure, the stress condition between various components of the valvetrain will be significantly deteriorated, and the single quenching process can no longer meet the engine's requirements. At present, researchers have introduced surface modification technology into the manufacturing of valvetrain components. For example, Lawes et al. [6] coated engine valve-tappet surfaces with two types of hydrogenated and non-hydrogenated diamond-like carbon films, which improved the abrasion performance of tappet. This class of coating materials has also been widely reported in other studies [7-9]. Lai et al. [10] proposed that ultrasonic surface rolling could be introduced to the processing of 33Cr23Ni8Mn3N (23-8N) austenitic engine valve steel, and nanoscale surface strengthening structures can be formed on the outmost surface. Gangopadhyay et al. [11] also proposed applying shot peening technology to tappet shims, but the larger surface roughness did not bright the expected effect of reducing friction force. Generally speaking, these new surface modification technologies can be really applied to the engine still need to be examined and verified over a long period of time. Other techniques include chemical surface modification, in which active nonmetallic atoms are infiltrated into the surface of steel to obtain a certain thickness of non-metallic element-reinforced structure. Through decades of development, surface nonmetallic element infiltration technology has become a common technology to improve the wear resistance and structural performance of some high-performance components. Nitriding and carburizing techniques are representative. The nitrided steel can be characterized with higher hardness, wear resistance, and bite resistance. However, the thickness of the nitrided layer generated after nitriding treatment is generally no more than $500 \mu \mathrm{m}$, with large brittleness, easy cracking, and high cost [12-14]. Carburizing can achieve similar hardness and anti-wear performance, and have enough depth of carburized layer (up to $2 \mathrm{~mm}$ ). Therefore, the carburizing treatment is still one of the most acceptable surface modification technologies for the low carbon steel components in heavy-duty commercial vehicle engines. 
Presently, the main wear behaviors of some tribo-pairs in a valvetrain, such as cam-follower, valve-seat, valve-valve guide, and cam-rocker arm, have been clarified widely, and many of these conclusions provide a lot of reference for engine design [15,16]. Simultaneously, although surface enhancement treatments with carburizing has been developed for many components and types of materials, little research on valve rocker-valve rocker bracket tribo-pair components and materials can be found in the published literature. In this paper, in order to investigate the influence of carburizing treatment on fretting wear characteristics and wear mechanism of valve rocker-valve rocker bracket tribo-pair, 20CrMnTi steel was taken as the target material and fretting test was carried out by an oscillating reciprocating friction and wear tester. Subsequently, this work further evaluated the fretting wear behaviors of carburized 20CrMnTi steel under different loads (corresponding to different engine power output) and different frequencies (corresponding to different engine speed), and the related wear mechanisms were also analyzed and discussed.

\section{Material Preparation and Experimental Methods}

\subsection{Material Preparation}

The material selected for use in this work, 20CrMnTi steel has a strong oxidation resistance, corrosion resistance and abrasion resistance, which is commonly used material for valvetrain component in modern internal combustion engines, such as camshaft, valve rocker attachments and valve rocker bracket [17]. The $20 \mathrm{CrMnTi}$ steel bar was provided by a commercial material supplier with normalizing state. In order to facilitate the heat treatment and fretting wear tester clamping, it is further divided into small specimens of $\Phi 24 \mathrm{~mm} \times 8.0 \mathrm{~mm}$. The typical chemical compositions of 20CrMnTi steel are presented in Table 1.

Table 1. Typical chemical compositions of substrate (wt. \%).

\begin{tabular}{cccccccc}
\hline $\mathbf{C}$ & $\mathbf{S i}$ & $\mathbf{M n}$ & $\mathbf{P}$ & $\mathbf{S}$ & $\mathbf{C r}$ & $\mathbf{T i}$ & $\mathbf{F e}$ \\
\hline 0.225 & 0.244 & 0.810 & $\leq 0.05$ & $\leq 0.05$ & 1.044 & 0.065 & Balance \\
\hline
\end{tabular}

According to the working condition of shaft steel, there are two types of major finishing processing technologies for 20CrMnTi steel, including quenching process and carburizing process. Therefore, in this paper, two kinds of material states of virgin state, quenched state were set up and compared with carburized state. A gas carburizing furnace (RM3-45-9D, Shanghai electric furnace co. LTD, Shanghai, China) was used to carburize with methanol and kerosene mixture as the infusion solution. It is well known that low hardness decarburization layer is easily produced after ordinary quenching. For this reason, the quenched specimen should be removed by grinding about $2-3 \mathrm{~mm}$ to avoid the influence. The parameters for heat treatment were selected based on the material properties of 20CrMnTi steel, and the diagrams of each heat treatment process are presented in Figure 2. In order to obtain a higher depth of hardened carburized layer, the specimens were carburized at $920^{\circ} \mathrm{C}$ for $210 \mathrm{~min}$.
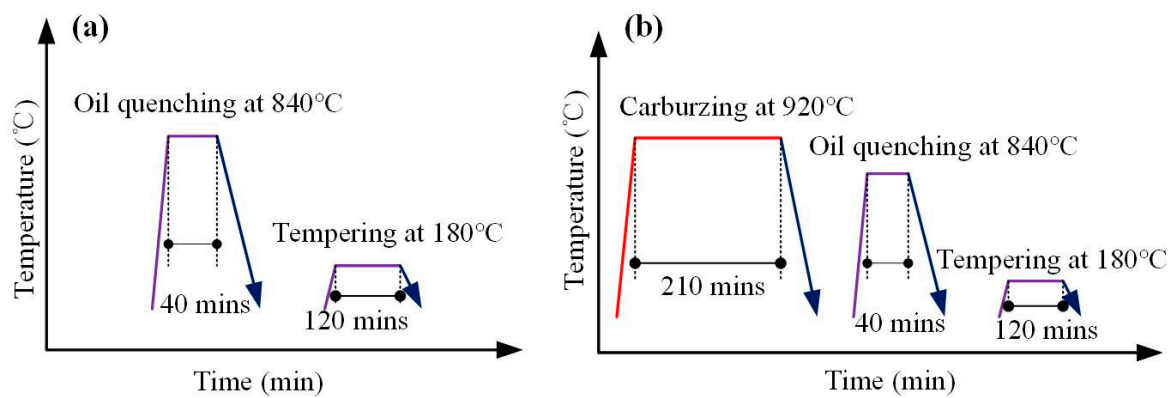

Figure 2. The diagram of heat treatment process for $20 \mathrm{CrMnTi}$ steel: (a) quenching, (b) carburizing. 


\subsection{Microstructure Characterization}

After the same grinding process was applied to each specimen, a 3D optical profilemeter (BMT Expert, BMT, Karlsruhe, Germany) was used to measure and ensure that the roughness of all surface was similar. Each of specimens are properly ground to make the surface clean and smooth, and the surface roughness reaches about $\mathrm{Ra}=0.54 \mu \mathrm{m}$. In order to characterize the microstructure evolution of the specimen before and after heat treatment, the specimen was polished by polisher and then corroded with 4\% Nital, respectively. The scanning electron microscope (SEM; Quanta 200, FEI, Hillsboro, OR, USA) was used to observe the microstructure of the corroded specimens. Microhardness tester (HVS-1000, SCTMC, Shanghai, China; applied load of $100 \mathrm{gF}(0.98 \mathrm{~N})$, dwelling time of $15 \mathrm{~s})$ was used to measure the hardness in depth direction of the carburized specimen, so as to determining the thickness of carburized layer of specimen. The average hardness test on the same depth section should not be less than 6 times to ensure the test accuracy and repeatability.

\subsection{Fretting Wear Test}

The fretting wear properties of specimens was studied by an oscillating reciprocating friction and wear tester (SRV IV, Optimol, Munich, Germany) under dry condition. Based on the actual service conditions of valve rocker-valve rocker bracket tribo-pair, ball-on-disc contact was selected as the contact form for the test. The 45 steel is also commonly used in valve manufacturing [18]; therefore, it was selected as the rocker arm material to be paired with 20CrMnTi steel in this work. After intermediate frequency quenching, the upper spherical specimen with a diameter of $10 \mathrm{~mm}$ can be cut from the commercialized 45 steel bar (hardness of $59 \mathrm{HRC}$ ). Before and after the fretting test, all specimens would be cleaned by ultrasonic cleaning machine in anhydrous ethanol. The dried specimen was stored in a desiccator to avoid contamination. All fretting tests were carried out at room temperature. In the study of effect of carburizing treatment on wear behaviors of 20CrMnTi steel, the fretting tests are carried out under the parameters in Table 2. In order to further explore the wear behavior of carburized 20CrMnTi steel under different potential working conditions, tests are carried out according to the parameters in Table 3. The fretting test under each set test parameters was repeated for three times.

Table 2. Fretting wear parameters for specimens under different heat treatment conditions.

\begin{tabular}{cccc}
\hline Load $(\mathbf{N})$ & Stroke $(\mu \mathrm{m})$ & Frequency $\mathbf{( H z )}$ & Time $(\mathbf{s})$ \\
\hline 30 & 200 & 10 & 1800 \\
\hline
\end{tabular}

Table 3. Fretting wear parameters for specimens under different load and reciprocating frequency conditions.

\begin{tabular}{ccccc}
\hline \multirow{2}{*}{ Variable Index } & \multicolumn{4}{c}{ Test Parameter } \\
\cline { 2 - 5 } & Load (N) & Time (s) & Frequency (Hz) & Stroke $(\mu \mathbf{m})$ \\
\hline Load & $50,100,150,200$ & 1800 & 10 & 200 \\
Frequency & 150 & 1800 & $5,10,15,20$ & 200 \\
\hline
\end{tabular}

Based on the 3D surface morphology of the worn surface after fretting testing, the measured values of wear scars in the transverse, longitudinal and depth directions can be obtained respectively. Then, the WVL $\left(V_{s}\right)$ of specimen can be calculated by Equation. 1 and Equation (2) as follows:

$$
\begin{gathered}
R=\left(d_{q} \cdot d_{s} / 4+h^{2}\right) / 2 h \\
V_{s}=\pi h^{2}(3 R-h) / 3
\end{gathered}
$$


where $R$ is the radius of curvature of the worn surface, $d_{s}$ and $d_{q}$ are the length of wear scar in the fretting direction and the width perpendicular to the fretting direction respectively, $h$ is the depth of the wear scar.

\section{Results and Discussions}

\subsection{Microstructure}

The surface microstructure of specimen at virgin state and carburized state are presented in Figure 3. As shown in Figure 3a, the main microstructures in the metallographic at virgin state are pearlite and white netted ferrite, which are uniformly distributed in the surface. After carburizing, a large number of granular cementites with different sizes appeared in the outmost layer of the specimen (Figure 3b). The boundary of these granular cementites was smooth and evenly distributed, and it was observed that there are acicular martensite and retained austenite in the subsurface layer. According to EDS results (as shown in Figure 3c), a large number of $\mathrm{C}, \mathrm{Fe}, \mathrm{Mn}, \mathrm{Cr}$, and Ti elements were found therein the granular cementites labeled in Figure 3b. Shein et al. [19] has reported that the presence of $\mathrm{Cr}$ and Ti elements own a stabilizing effect on cementites. Medvedeva et al. [20] explained that $\mathrm{Cr}$ substitution increases the cohesive energy, which they interpret as a stabilization of cementites. Stable cementite can not only increase the hardness and strength of the substrate, but also avoid the stress concentration in contact with friction specimens or abrasive debris because of its angular boundary [21-23]. Therefore, it can be inferred that the crack propagation on carburized specimen can be hindered during fretting wear, which plays an important role in improving the wear resistance of specimens. At the same time, the formation of acicular martensite can be observed on the specimen surface after quenching, which will be helpful to increase the grain boundary slip resistance in the wear process and improve the wear resistance of material.
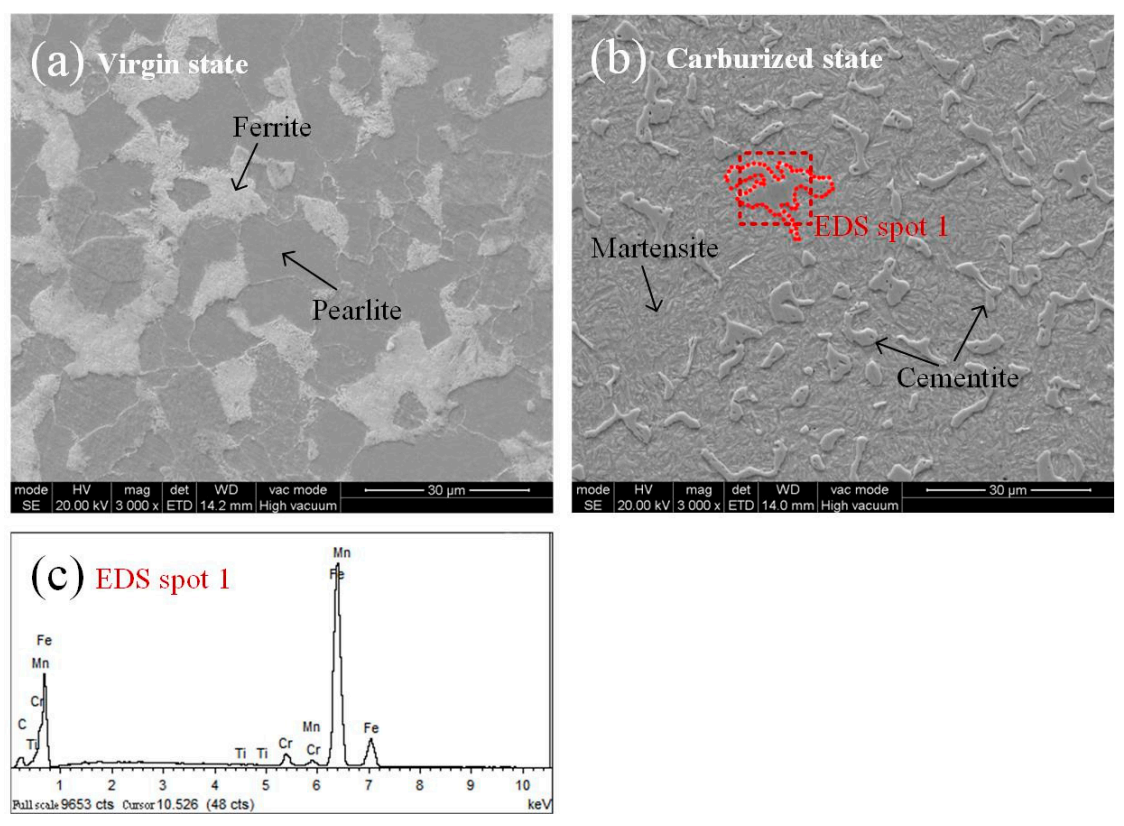

Figure 3. The SEM microstructures of $20 \mathrm{CrMnTi}$ steel: (a) virgin state, (b) carburized state; and (c) EDS result of cementites.

\subsection{Microhardness}

Hardness reflects the elastic and plastic deformation ability of the material intuitively [24]. The surface microhardness results of each state of the steel are shown in Figure 4. It can be seen that the surface microhardness of specimen at quenched state and carburized state was $90.4 \%\left(\sim 476 \mathrm{HV}_{0.1}\right)$ and $200 \%\left(\sim 750 \mathrm{HV}_{0.1}\right)$ higher than that of virgin steel (i.e. substrate; $\left.250 \mathrm{HV}_{0.1}\right)$, respectively. This is 
due to the cementite and martensite formed after carburizing and quenching are greater in hardness and strength than ferrite and pearlite before heat treatment. Through the cross-section observation of untreated specimen specimens, it was found that the cross-section microhardness of carburized specimens changed along the depth gradient (Figure 5). With the increase of depth, the hardness gradually decreased to the level at quenched state (surface hardness of quenched specimen), while the thickness of effective hardened layer after carburizing can reached about $1.2 \mathrm{~mm}$.

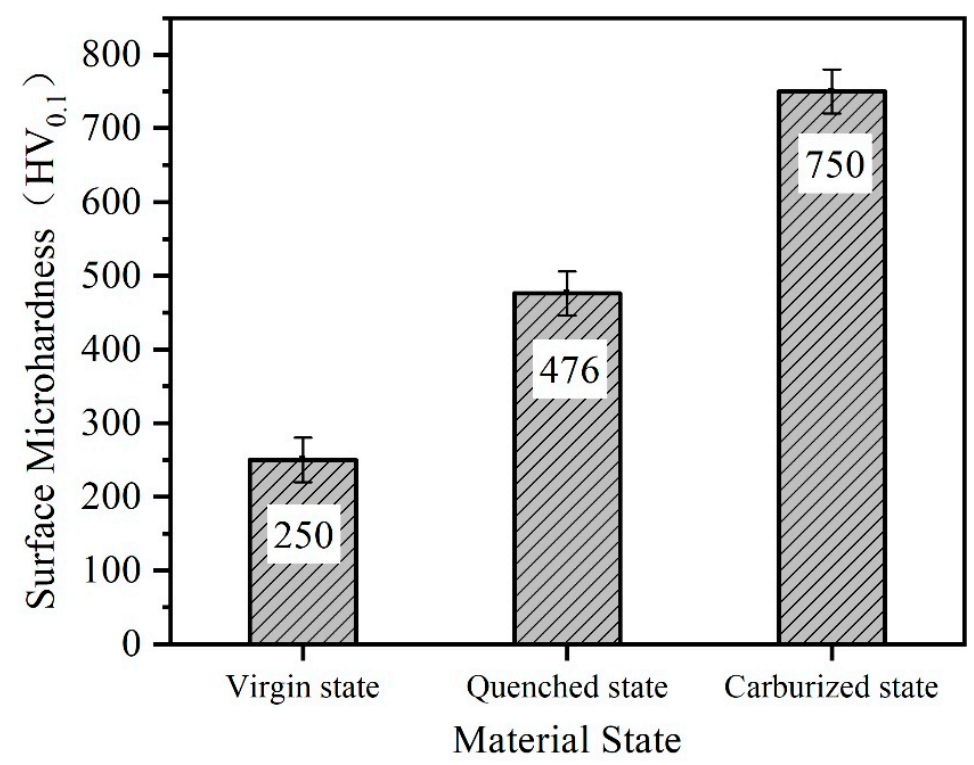

Figure 4. Surface microhardness of specimens under different material state.

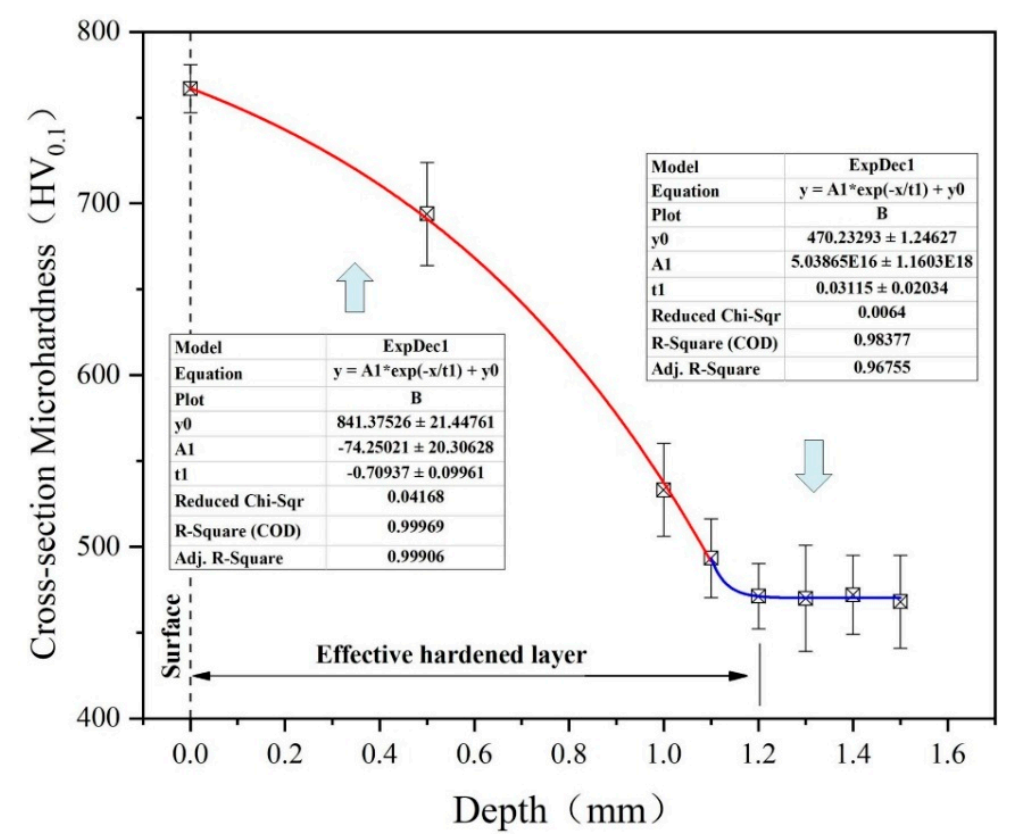

Figure 5. The cross-section microhardness of carburized specimen along the depth.

\subsection{Effect of Carburizing Treatment on Wear Behaviors}

\subsubsection{Coefficient of Friction}

Figure 6 presents the dynamic coefficients of friction (CoFs) and average CoFs of the tribo-pairs under different material states. At the early stage, asperities of friction specimens are in contact with each other, forming local spot welding. With the development of reciprocating motion, spot welding 
gradually tears apart, resulting in all test groups CoFs are rising trend. Under the co-action of contact pressure and surface shear stress, plastic deformation occurred on the specimen surface. After quenching and carburizing treatment, the dynamic CoF of the specimen surface was lower than that of the virgin state. It is speculated that the stronger plastic deformation of the specimens leads to working hardening, which can make the material surface more brittle and harder, and gradually falls off, forming abrasive debris. The generated debris can form an abrasive gray third body layer between the tribo-pairs, and participate in the bearing effect, so that the tribo-pair can be separated, the wear and $\mathrm{CoF}$ is also decreased $[25,26]$. Entering the worn stable period, the CoF of all specimens is gradually stabilized, which is attributed to the wear debris is constantly produced and discharged in the process of friction, forming a dynamic balance. It is obviously that the average CoF of carburized specimens is significantly lower than that of specimens in virgin state and quenched state. Therefore, it can be concluded that the better friction characteristic of the carburized specimen contributes to the reduction of energy loss and probability of thermal ablation during the swing of the rocker arm as compared to the specimens in other states.

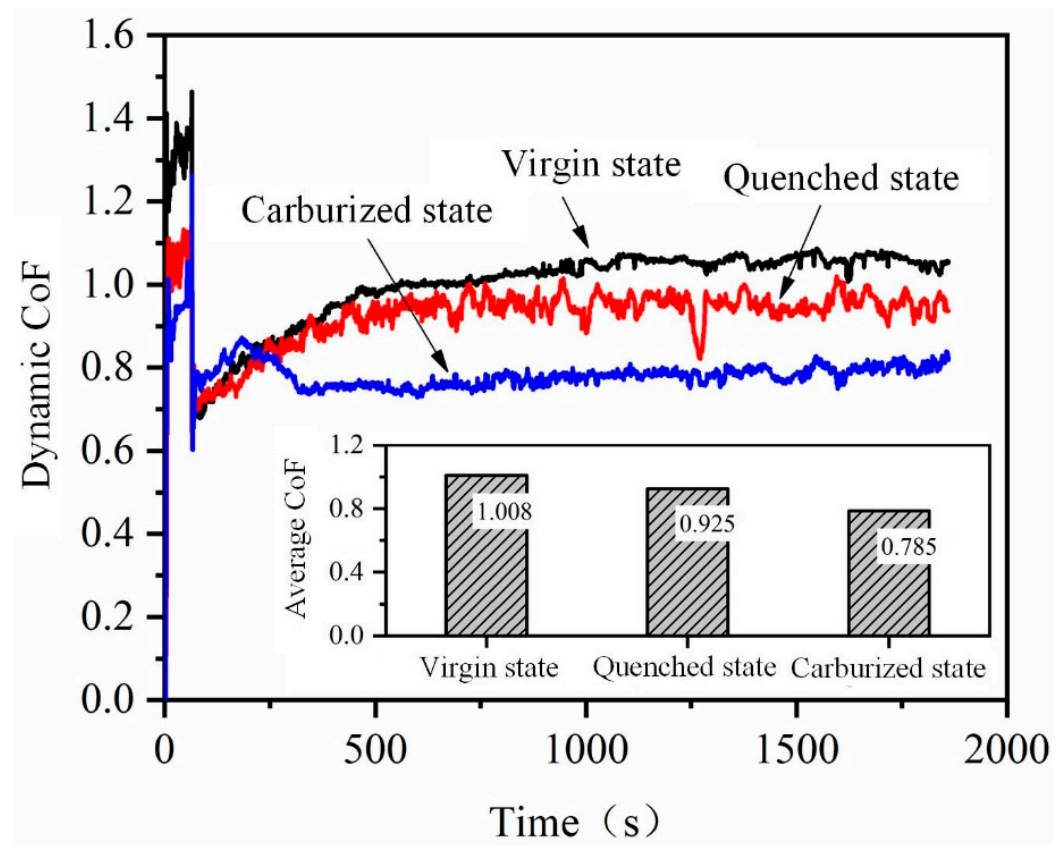

Figure 6. The coefficient of friction $(\mathrm{CoF})$ of the tribo-pairs under different material states.

\subsubsection{Wear Volume Loss}

Figure 7a shows the cross-section profile of specimens at each material state perpendicular to the direction of fretting wear. It can be found that the maximum depth of wear scars was $28.9 \mu \mathrm{m}$ at virgin state, $13.9 \mu \mathrm{m}$ at quenched state and $8.85 \mu \mathrm{m}$ at carburized state. It can be explained that the low surface hardness and the worst adhesive wear resistance of virgin steel. Under the co-action of normal load and shear force, the particles and fragments generated by adhesive wear embeds the surface layer and leads to the formation of ploughing. This can be represented as a sharp serrated line in the section profile. At the same time, when spot gluing further occurs, larger particles will fall off from the soft substrate, resulting in deeper spalling points. After carburizing, the surface hardness of specimen was further improved, and the resistance ability of adhesive wear was enhanced, so that the surface adhesive particles were significantly reduced. Based on Equations (2) and (3), the WVL of each material state during fretting wear can be obtained (as shown in Figure $7 \mathrm{~b}$ ). According to the histogram, the WVL of the specimens measured at carburized state was $3.80 \times 10^{-3} \mathrm{~mm}^{3}$, which was $72.1 \%$ and $46.5 \%$ lower than that in virgin state and quenched state. The results indicate that the carburizing treatment for $20 \mathrm{CrMnTi}$ steel is beneficial to significantly enhance the wear performance. 
The high hardness of carburized layer assists to reduce the adhesive particle and debris formation on the surface. It is believed that stress concentration easily leads to crack formation [27,28]. Therefore, the uniformly distributed non-angular cementite in the carburized layer is positive to prevent the crack initiation. The strength and toughness of substrate are also guaranteed due to the reduction of material fatigue spalling, and the WVL can be reduced.
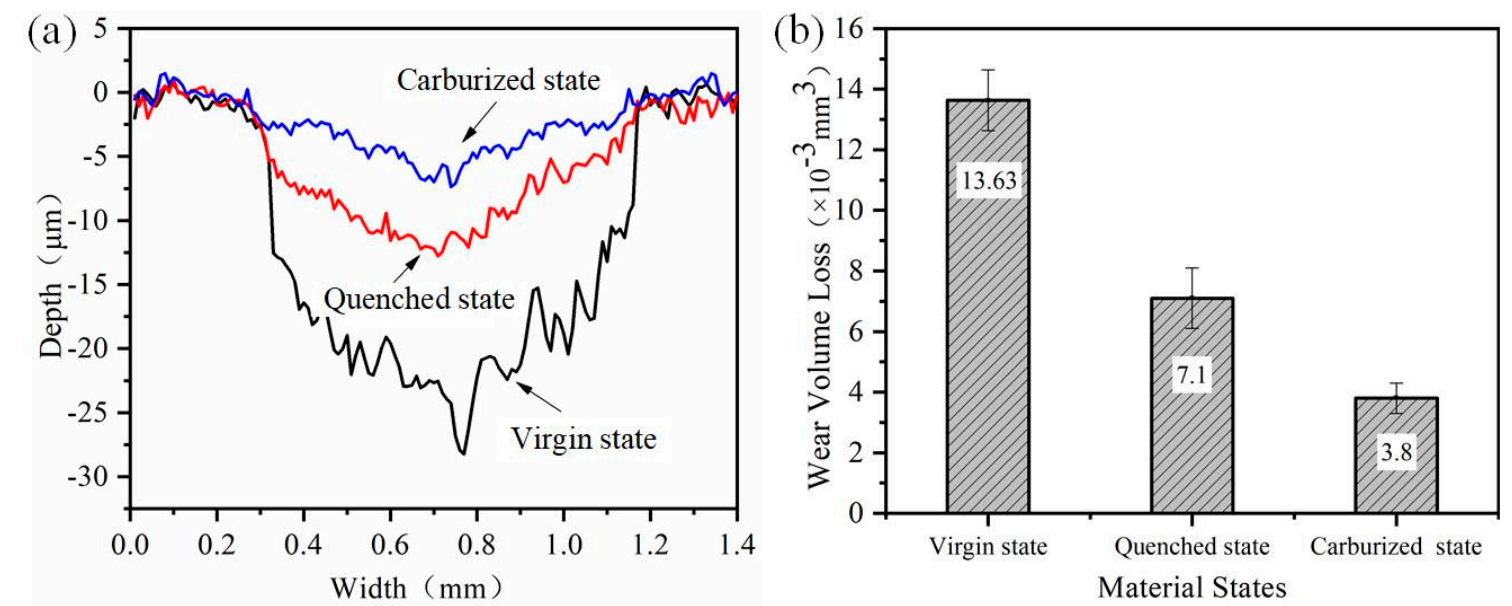

Figure 7. The wear characteristics of 20CrMnTi at different material state: (a) cross-section profiles of wear scars and (b) wear volume loss (WVL) of specimen.

\subsubsection{Variation of Wear Mechanism}

Figure 8 shows the specimen surface worn in SEM micrographs of each material state after the fretting test. It can be found that a lot of deeper ploughings (or scratches) and small spalling pits parallel to the fretting direction were formed on the surface of virgin specimen, which are the main features of abrasive wear and adhesive wear (Figure 8a). This is mainly due to the low surface hardness, poor adhesive wear resistance of the virgin steel, and mutual contact of asperities. When the normal load is applied, gluing and other phenomena are likely to occur, thus forming spalling pits and generating wear debris. In addition, the abrasive debris squeezed by load will act as the asperities being pressed into the surface of the lower specimen, generating high local stress and ploughing structure under the action of friction force, thus resulting in "third-body wear". After quenching, the ploughing phenomenon found on the surface of virgin steel was disappeared, it indicates that abrasive wear is improved to some extent (Figure 8b). Meanwhile, delamination formed by a large area of brittle fracture was observed on the surface, with some unpeeled oxide films. The wear mechanism is presented as a mixed mechanism of adhesive wear, abrasive wear, and oxidative wear. For a long time, it has been recognized that the improvement of hardness can improve the adhesive wear resistance, scoring resistance, and fatigue strength of carbon steel [29]. However, generally, the fracture toughness decreases with the increase of hardness after quenching, so it will increase the abrasive wear $[30,31]$. The local raised temperature produced during the friction is the primary cause of the oxidative wear [32]. Higher temperature will promote the oxidative of deformation layer to form oxide film, which is more prone to brittle fracture, however, the peeling oxide film further aggravates the oxidative wear. Therefore, oxidation is a vital factor to promote fretting wear. After carburizing, the direct contact of each metal substrate in the tribo-pair was avoided by carburized layer, and the ploughing effect caused by abrasive debris was also further reduced (Figure 8c). There was also a large area of black oxide film and a small spalling pit observed on the surface. The wear mechanism showed a mixed mechanism of abrasive wear, adhesive wear, and oxidative wear. Compared with quenching, the delamination can have been significantly reduced. Although the increase of the same hardness leads to the decrease of fracture toughness, the presence of the second phase of cementite makes the surface strain hardening rate increase and the tendency of work hardening more obvious [33]. According to Rabinowitz's theory, the brittle oxide film falls off and forms fine debris, which effectively 
fill the asperities and ploughings between the contact surfaces, so as to increase the contact area of the tribo-pair, reduce the contact stress. Therefore, this is why there are only slight adhesive pits on the surface of lower carburized specimen. Figure 8d extracts the EDS results of unworn and worn surfaces of a specimen at carburized state. It is confirmed that the percentage of oxygen element weight increases from 0 to $29.59 \%$ after wear, indicating that more severe oxidation takes place. Lim et al. [34] mentioned that the presence of the oxide film should be due to the formation speed of the oxide film being greater than the removal rate. It is speculated that after carburizing, the anti-adhesive wear performance of the specimen surface is enhanced, and the spalling rate decreased, so that more oxide film can be observed.
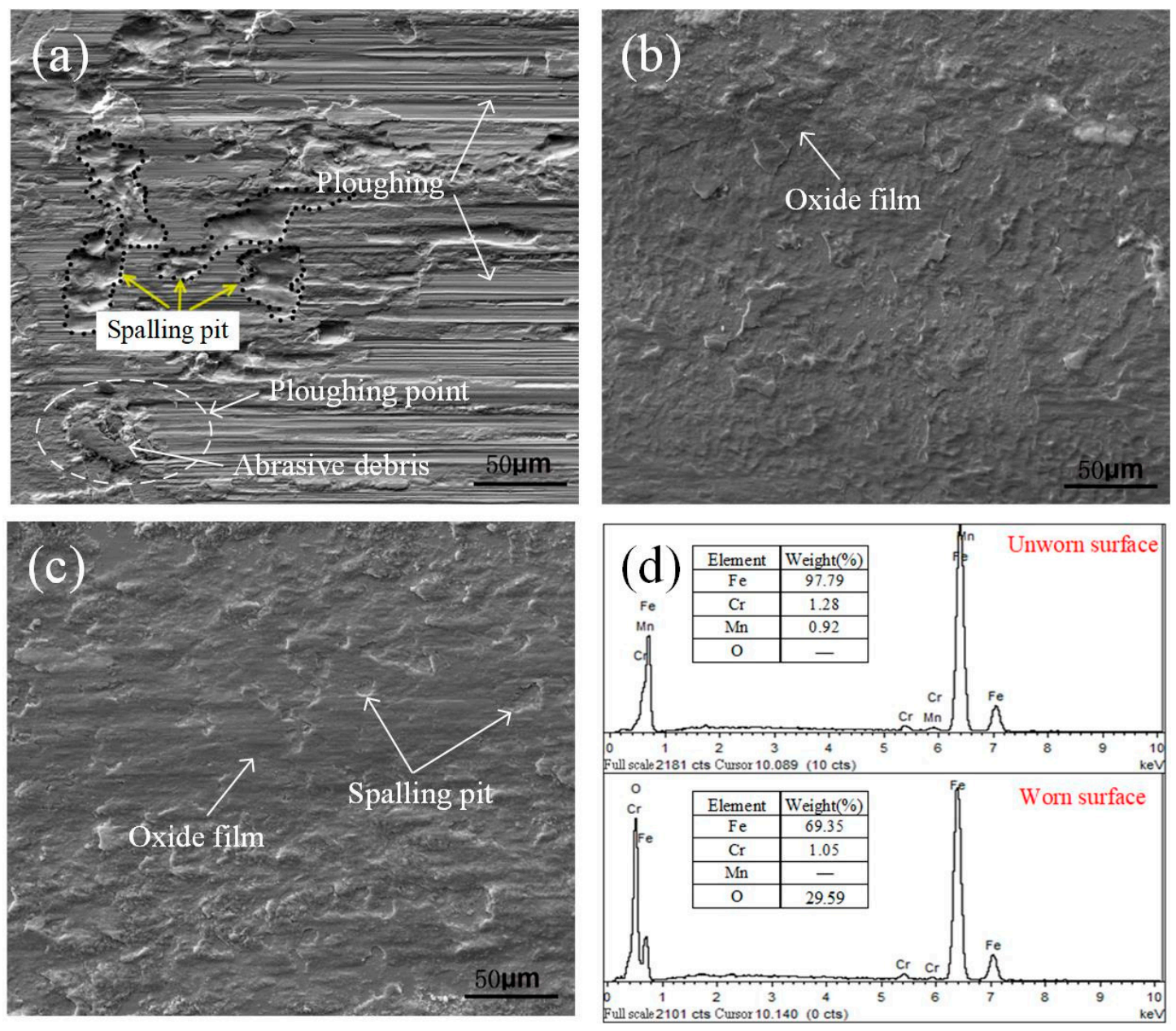

Figure 8. The surface worn SEM micrographs of specimen under different material state: (a) virgin state, (b) quenched state, (c) carburized state; and (d) EDS results of carburized specimen.

\subsection{Wear Behaviors of Carburized State under Different Loads and Reciprocating Frequencies}

\subsubsection{Coefficient of Friction}

It is obvious that the carburizing treatment is significant to reduce the CoF and WVL of 20CrMnTi steel. Although the service conditions of modern diesel engines are complicated, engine power and speed are still the basic variables that affect the performance of the whole engine. Therefore, it is necessary to further explore the wear performance of carburized 20CrMnTi steel by different loads and frequencies.

The CoF curves shown in Figure 9a were obtained by applying different loads to the tribo-pairs. When the load of the tribo-pair was increased, the dynamic CoF and the average CoF between the tribo-pairs decreased. Some viewpoints hold that this is attributable to the elastic-plastic contact state 
between the surface of the friction specimens, the CoF between the tribo-pairs in the case of fretting wear is mainly determined by two aspects: Firstly, Chen et al. [35] pointed out that the real contact area has a non-linear relationship with the load, and the increase of the load is different from the increase of the contact area. When the load increases, the increase rate of the load will be higher than the increase rate of the actual contact area, resulting in the reduction of the CoF. This was also reported in the research of Carey et al. [36]. Secondly, excessive load will usually damage the friction reaction film, resulting in an increase in the CoF [37]. However, due to the protection of the carburized layer, the damage of the friction reaction film is reduced, which has a small impact on the CoF. Thus, the CoF of the tribo-pair gradually decreases.
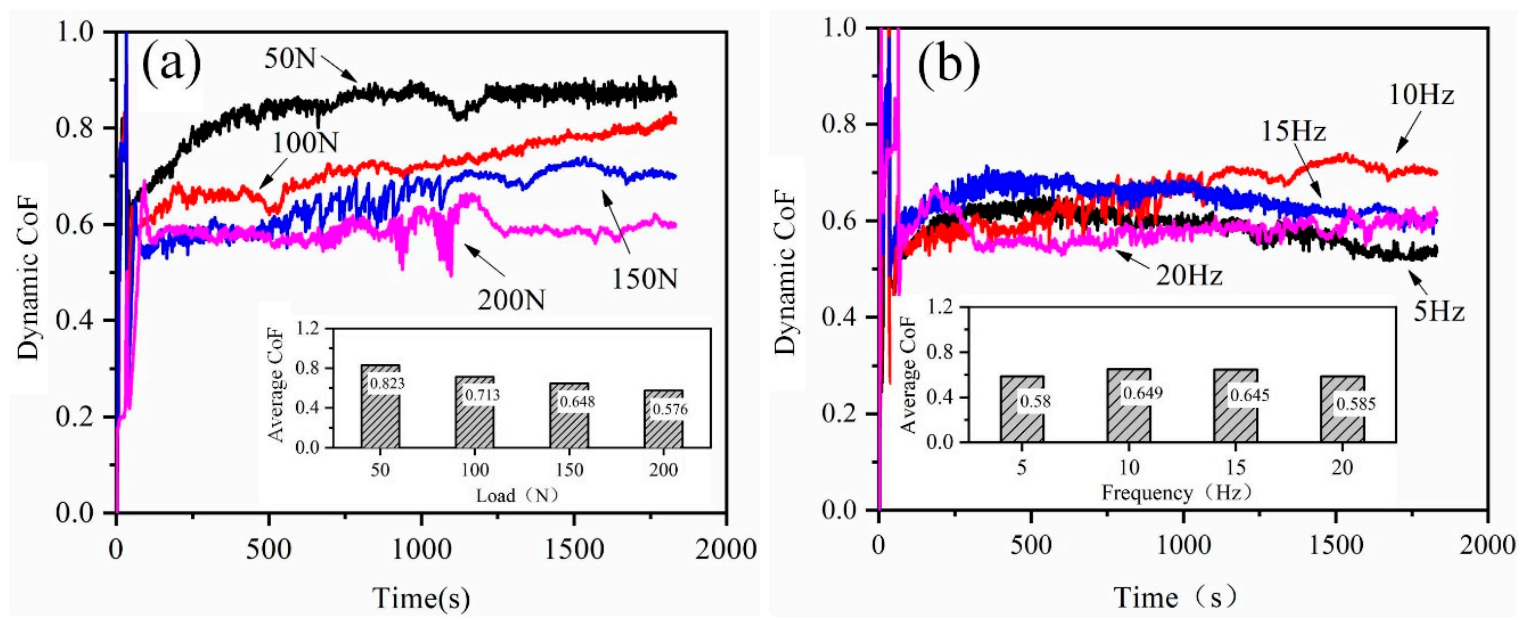

Figure 9. The CoF of tribo-pairs under different: (a) loads and (b) reciprocating frequencies.

The CoF between tribo-pairs under different reciprocating frequencies are shown in Figure $9 \mathrm{~b}$. Basically, the dynamic CoF between tribo-pairs increased first and then decreased with the increase of reciprocating frequency. It could be inferred that in the process of increasing the reciprocating frequency, the higher temperature softens the material surface, causing the CoF tends to increase first and then stabilize [38]. In addition, the accumulation of wear cycles is more rapid at higher speeds.

\subsubsection{Wear Volume Loss}

The WVL of 20CrMnTi steel under different loads and reciprocating frequencies are shown in Figure 10. It is observed that there is a positive correlation between the applied load and the WVL (Figure 10a). It is indicated that the increase of normal load results in an increase of adhesive wear of the specimen, and more adhesive pits were formed after the debris fell off. Meanwhile, the detached abrasive debris become abrasive particles, which cause micro-cutting action on the specimen surface under the action of friction, and the generated ploughings and grooves lead to higher wear loss. When the normal load circulates, stress concentration is also occurred easily on the friction surface, which promotes the extension of material removal. 


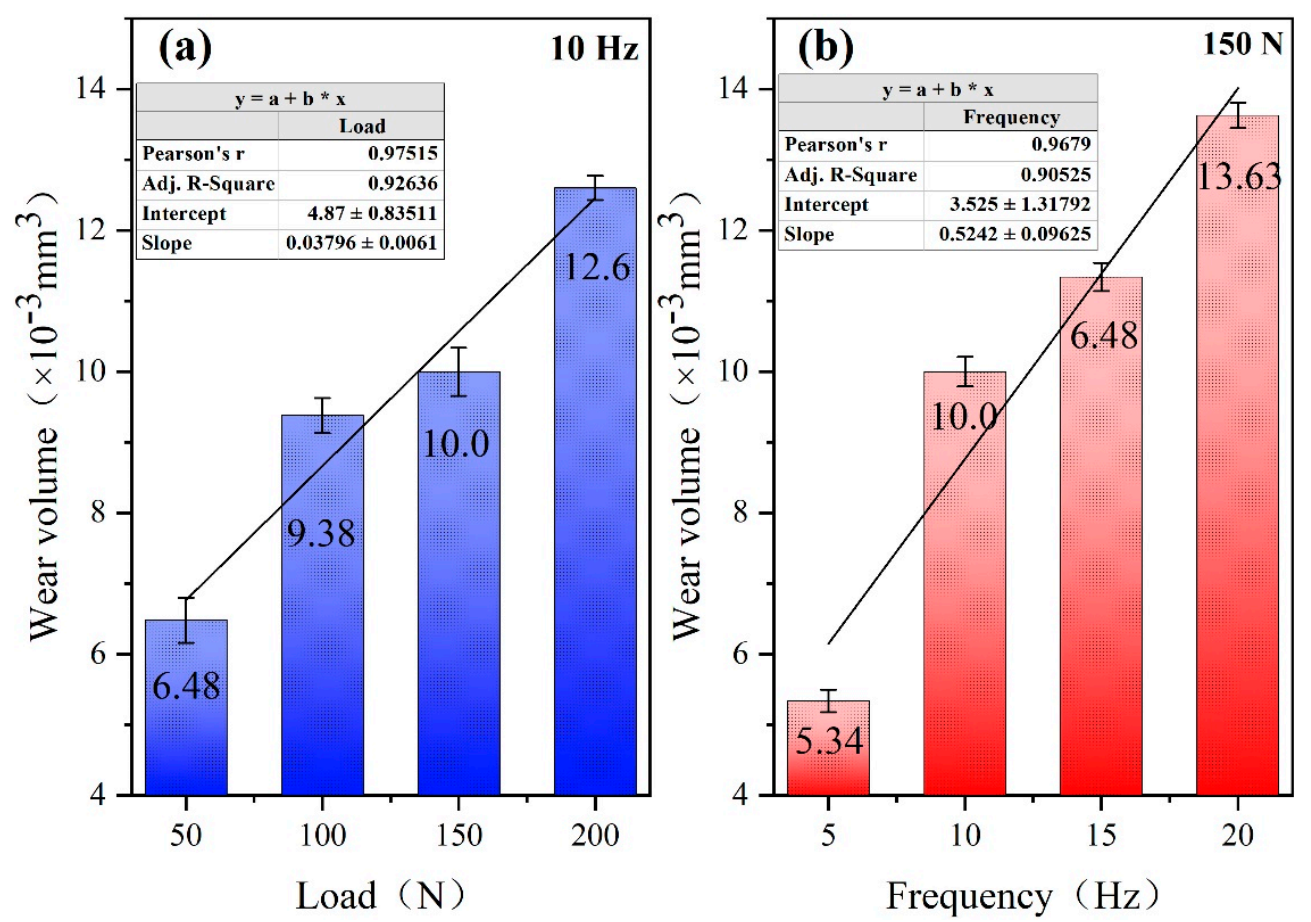

Figure 10. The WVL of each specimen with different: (a) loads and (b) reciprocating frequencies.

The variation of WVL was also increased with the increase of reciprocating frequency, which is similar to that of load change (Figure 10b). The flash temperature in the contact surface under the dry sliding conditions was in a high level [39]. Some researchers believed that the increase in frequency will increase the contact flash temperature and lead to the softening and high wear rate of the material [40]. Therefore, the softening of the specimen surface caused by high friction frequency will facilitate the abrasive debris generated by adhesive wear be squeezed into the specimen surface, thus producing stronger ploughing action and adhesive wear.

\subsubsection{Variation of Wear Mechanism}

Figure 11 shows the surface worn SEM micrographs of 20CrMnTi steel specimen under different loads. It can be seen that the area of fretting wear scar increased with the increase of load, a large amount of adhesive layer caused by adhesive wear can be observed outside the fretting wear area. According to the previous analysis, it can also be judged that this is due to the contact stress caused by the asperities on the frictional specimen surface. As shown in Figure 11a, no obvious ploughing and scratch had been discovered on the surface of the test specimens due to the existence of the strengthened layer, and the adhesive layer covered on the specimen surface was supposed to be from the upper specimen (i.e., 45 steel). The wear mechanism is primarily light-adhesive wear at low-load level. When the load was increased to $100 \mathrm{~N}$, the elliptical wear scar with a diameter of $91.32 \mu \mathrm{m}$ appeared on the surface of the specimen. By this time, the adhesive wear began to intensify, and a large number of excreted debris accumulated near the wear scar (Figure 11b). In terms of WVL, most of the accumulation adhesive layer came from the upper specimen. Zhang et al. [41] found that as the hardness of the rail matched material increases, the wear degree of the rail specimen becomes more and more serious. This indicates that most of the surface wear occurs on the softer side of the friction pair material, therefore, material hardness matching is crucial during the selecting of material for valve rocker-valve rocker bracket tribo-pair. When the load reached $150 \mathrm{~N}$, the diameter of the wear scar increased to $207.15 \mu \mathrm{m}$. As shown in Figure 11c, some abrasive particles existed on the worn surface and formed the "third-body" except to the upper and lower specimens. The results show that the wear mechanism is a mixed wear mechanism dominated by abrasive wear. Chen et al. [42] summarized the damage steps of fretting: a ploughing process during the initial stages of fretting, 
followed by oxidation and delamination, then "third-body" abrasive wear and expansion of the fretting scar during the steady-state behavior. Therefore, the specimen will gradually maintain a constant $\mathrm{CoF}$ after entering the third-body wear state and gradually expand the wear scar. Figure 11e presents the EDS results of unworn and worn surface of specimens at load of $150 \mathrm{~N}$ and reciprocating frequency of $10 \mathrm{~Hz}$. The result shows that the weight percentage of oxygen element increases from 0 to $31.8 \%$ after wear. It can be intuitively inferred from the energy spectrum that oxidative wear also occurs under $150 \mathrm{~N}$, and the frictional heat produced by fretting wear aggravates the oxidation of the wear debris and makes the oxidative wear of the specimen to be more severe. When the load reached $200 \mathrm{~N}$, it was observed that there were many oxide films and ploughings on the surface, and the diameter of the wear scar increased sharply to $507.97 \mu \mathrm{m}$ (Figure 11d). The wear mechanism is a mixed mechanism of abrasive wear and oxidative wear. In addition, the existence of a large number of oxide films also reflects the improvement of fatigue resistance. Some studies suggested that "third-body wear" can introduce a film that protects the cracks in fatigue wear and limits their propagation [43].
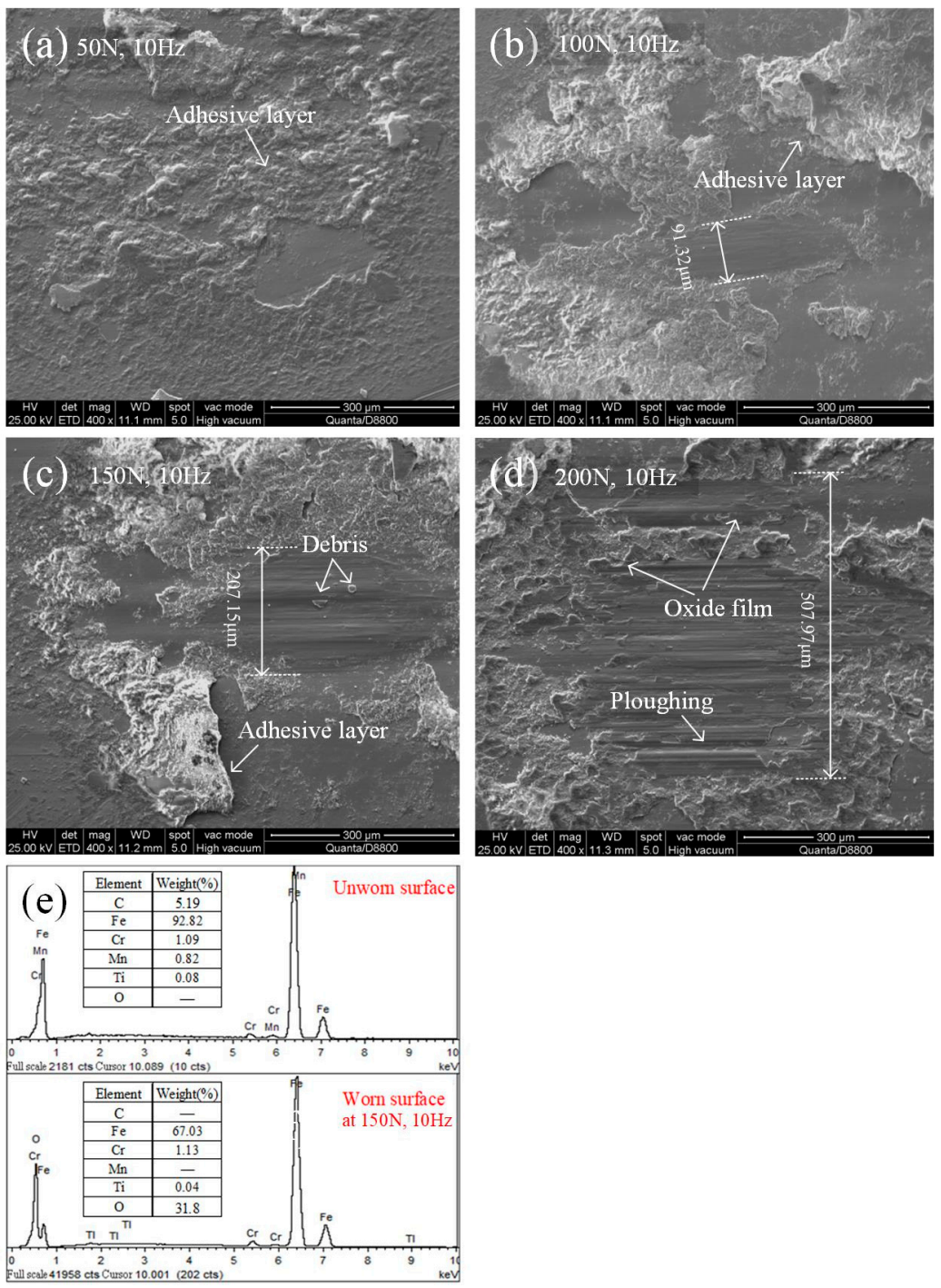

Figure 11. The surface worn SEM micrographs of specimen at loads of: (a) $50 \mathrm{~N}$, (b) $100 \mathrm{~N}$, (c) $150 \mathrm{~N}$ and (d) $200 \mathrm{~N}$; and (e) EDS results of unworn surface and the worn surface at $150 \mathrm{~N}, 10 \mathrm{~Hz}$.

The surface worn SEM micrographs of 20CrMnTi steel specimen under different frequencies are shown in Figure 12. The adhesive layer and various degrees of ploughings were observed on the specimen surface at all frequencies. Similar to the wear mechanisms under different loads, the asperities 
embedded on the surface of the frictional specimen lead to the formation of adhesive wear and abrasive particles, and further produce the ploughing. The constant increase of swing frequency will also make the flash temperature of the tribo-pair surface rise and softening occurs, promoting the generation of adhesive layer. At a frequency above $10 \mathrm{~Hz}$, the phenomenon that the abrasive debris changed from granular accumulation to large-area flake accumulation was particularly obvious. This also means that more severe adhesive wear has occurred. As previously analyzed, this may be attributed to the increase in frequency which increases the local contact flash temperature, and the local softening of the material aggravates the adhesive wear. In this paper, the width and depth of ploughings on the surface of each specimen are similar, and the diameter of wear scars ranged from 207 to $253 \mu \mathrm{m}$, showing no strict linear increase with increasing frequency. A small number of abrasive particles can be observed in wear area respectively, so it can be deduced that the degree of abrasive wear was basically the same at different frequencies. In the studies related to the effect of frequency, Yun et al. [44] conducted a study of Inconel 690TT super alloy and SUS409SS steel under different stroke and frequency. They found that the $\mathrm{CoF}$ and wear mode are more likely to be affected by stroke than frequency. Similar conclusions have been found to be applicable to titanium alloys [45] and part type of high-strength steels [46]. However, under the condition of $20 \mathrm{~Hz}$, some black oxide film and strip spalling pit can be seen on the smooth surface, indicating that the oxidative wear and fatigue wear intensified at high frequency. Thus, the frequency has little effect on the wear type as a whole. The wear mechanism under 5, 10, and $15 \mathrm{~Hz}$ conditions can be summarized as a mixed mechanism of adhesive wear and abrasive wear, or may be accompanied by slight oxidative wear. At a frequency of $20 \mathrm{~Hz}$, the surface is subject to the combined effects of abrasive wear, adhesive wear, fatigue wear, and oxidative wear.
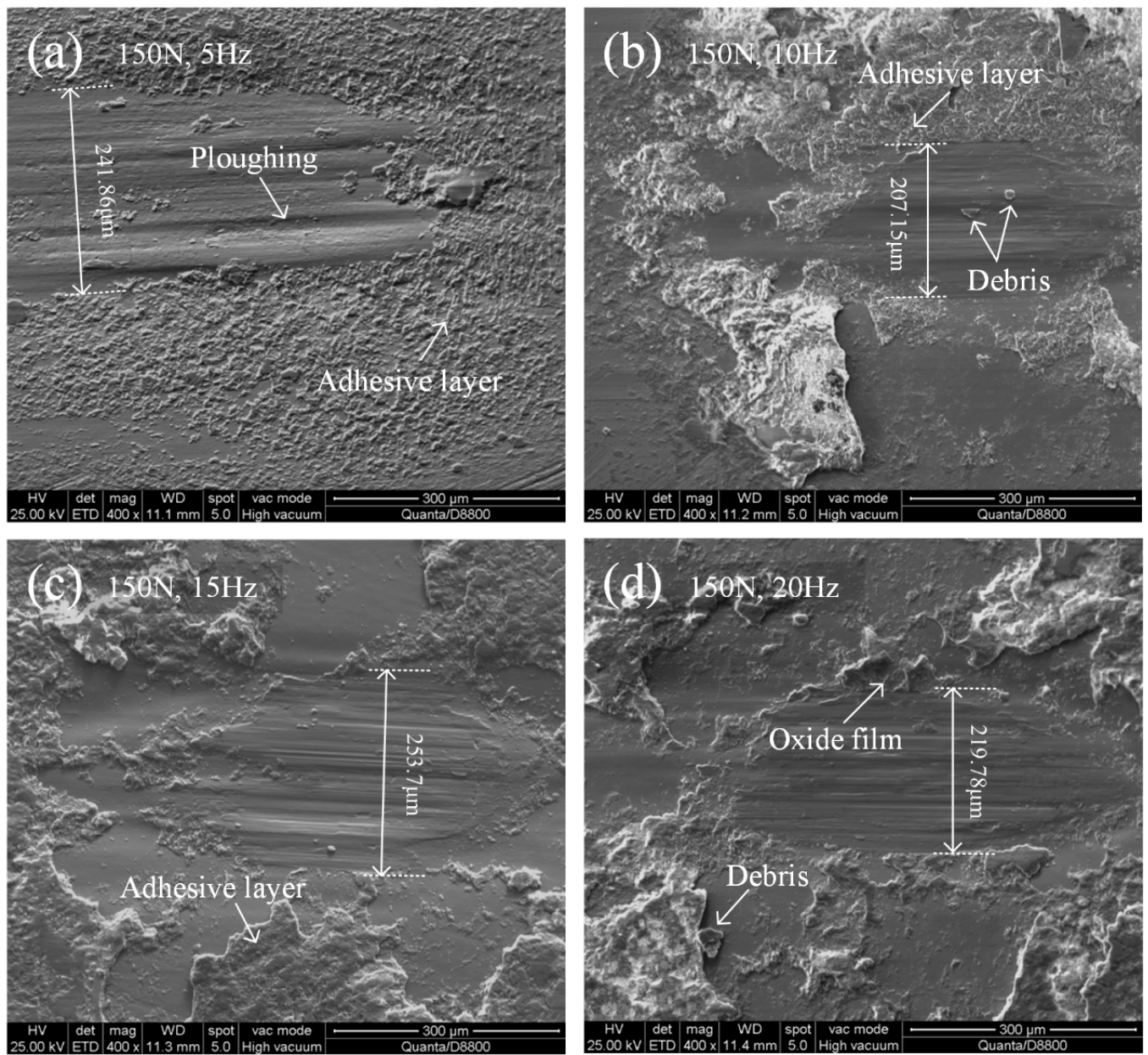

Figure 12. The surface worn SEM micrographs of specimen at frequencies of: (a) $5 \mathrm{~Hz},(\mathbf{b}) 10 \mathrm{~Hz}$, (c) $15 \mathrm{~Hz}$, and (d) $20 \mathrm{~Hz}$. 


\section{Conclusions}

In the present study, the influences of carburizing treatment, applied load, and reciprocating frequency on fretting wear behaviors of 20CrMnTi steel were investigated from the aspects of microstructure, coefficient of friction, wear volume loss, and wear mechanism. The main conclusions can be drawn as follows:

(1) After carburizing, the microstructure of 20CrMnTi steel was changed from a ferrite martensite structure to acicular martensite and a cementite structure, and the effective hardened thickness of carburized layer was about $1.2 \mathrm{~mm}$. The coefficient of friction of carburized specimens was lower than that of virgin state and quenched state, and the wear volume loss of the specimens can be reduced by $46.5 \%$ and $72.1 \%$, respectively, compared with virgin and quenched states.

(2) The wear mechanisms of the specimen at virgin state are primarily abrasive wear and adhesive wear. The wear mechanisms of the specimen surface after quenching are similar, but accompanied by slight oxidative wear. Carburizing treatment increases the ratio of surface abrasive wear and oxidative wear, but fatigue wear is significantly inhibited.

(3) When the load was increased from 50 to $100 \mathrm{~N}$, the surface wear mechanism of the specimens indicated that the degree of adhesive wear gradually increased, and some oxidative wear were observed. With the load was increased from 150 to $200 \mathrm{~N}$, it gradually turned into a variety of mixed mechanisms dominated by abrasive wear, and the oxidative wear increased with the increase of load.

(4) With the increase of reciprocating frequency, the surface wear mechanisms of the specimens are basically similar, which are mainly composed of adhesive wear and abrasive wear. Slight fatigue wear and more severe oxidative wear were observed at only 5 and $20 \mathrm{~Hz}$, respectively.

Author Contributions: Conceptualization, J.T. and F.L.; methodology, X.H.; software, X.H.; validation, F.L., X.H. and S.Q.; formal analysis, S.Q.; investigation, R.H.; resources, X.G.; data curation, X.G.; writing-original draft preparation, X.H. and J.T.; writing-review and editing, F.L. and S.Q.; visualization, R.H. and J.L.; supervision, J.T.; project administration, S.Q.; funding acquisition, J.L. All authors have read and agreed to the published version of the manuscript.

Funding: The authors would like to thank the Open Fund of National Engineering Research Centre of Near-net-shape Forming Technology for Metallic Materials (2019002) for their financial support of this research.

Conflicts of Interest: The authors declare no conflict of interest. The funders had no role in the design of the study; in the collection, analyses, or interpretation of data; in the writing of the manuscript, or in the decision to publish the results.

\section{Nomenclature}

CoF
WVL/Vs
$R$
$d_{s}$
$d_{q}$
$h$

coefficient of friction

wear volume loss $\left(\mathrm{mm}^{3}\right)$

curvature radius of the worn surface $(\mu \mathrm{m})$

length of the wear scar in the fretting direction $(\mu \mathrm{m})$

width of the wear scar perpendicular to the fretting direction $(\mu \mathrm{m})$

depth of the wear scar $(\mu \mathrm{m})$

\section{References}

1. Pandey, A.P. Effects of High Temperature on the Microstructure of Automotive Engine Valves. Int. J. Eng. Res. Appl. 2014, 4, 122-126.

2. Flett, J.; Bone, G.M. Fault detection and diagnosis of diesel engine valve trains. Mech. Syst. Sig. Process. 2015, 72-73, 316-327. [CrossRef]

3. Wang, Y. Introduction to engine valvetrains; SAE: New York, NY, USA, 2007.

4. Ajayi, O.O.; Alzoubi, M.F.; Erdemir, A.; Fenske, G.R. Effect of Carbon Coating on Scuffing Performance in Diesel Fuels. Tribol. T. 2001, 44, 298-304. [CrossRef] 
5. Xu, X.L.; Gao, Y.; Yu, Z. Fatigue fracture of a truck diesel engine rocker-bracket. J. Fail. Anal. Prev. 2013, 13, 340-345. [CrossRef]

6. Lawes, S.; Hainsworth, S.V.; Fitzpatrick, M.E. Impact wear testing of diamond-like carbon films for engine valve-tappet surfaces. Wear 2010, 268, 1303-1308. [CrossRef]

7. Johnston, S.V.; Hainsworth, S.V. Effect of DLC coatings on wear in automotive applications. Surf. Eng. 2005, 21,67-71. [CrossRef]

8. Gangopadhyay, A.; Sinha, K.; Uy, D.; McWatt, D.G.; Zdrodowski, R.J.; Simko, S.J. Friction, wear, and surface film formation characteristics of diamond-like carbon thin coating in valvetrain application. Tribol. T. 2010, 54, 104-114. [CrossRef]

9. Kano, M. DLC coating technology applied to sliding parts of automotive engine. New Diamond Front. Carbon Technol. 2006, 16, 201-210.

10. Lai, F.; Qu, S.; Lewis, R.; Slatter, T.; Fu, W.; Li, X. The influence of ultrasonic surface rolling on the fatigue and wear properties of 23-8N engine valve steel. Int. J. Fatigue 2019, 125, 299-313. [CrossRef]

11. Gangopadhyay, A.; McWatt, D.G. The effect of novel surface textures on tappet shims on valvetrain friction and wear. Tribol. T. 2008, 51, 221-230. [CrossRef]

12. Lipiński, D.; Ratajski, J. Modeling of Microhardness Profile in Nitriding Processes Using Artificial Neural Network. In Advanced Intelligent Computing Theories and Applications. With Aspects of Artificial Intelligence; Springer: Berlin, Heidelberg, Germany, 2007; Volume 4682, pp. 245-252.

13. Pellizzari, M.; Molinari, A.; Straffelini, G. Thermal fatigue resistance of gas and plasma nitrided 41CrAlMo7 steel. Mat. Sci. Eng. A 2003, 352, 186-194. [CrossRef]

14. Han, D.; Hong, W.; Choi, H.S.; Lee, J.J. Inductively coupled plasma nitriding of chromium electroplated AISI 316L stainless steel for PEMFC bipolar plate. Int. J. Hydrogen Energy 2009, 34, 2387-2395. [CrossRef]

15. Xia, Q.; Xiao, Q.; Cheng, C.; Zhao, D. Analyze and test of the abnormal wear between the cam and rocker arm. Vehicle Engine 2008, s1, 136-139.

16. Guo, H.; Zhuo, B.; Peng, J.; Lin, G. Lubricating study of valve-valve guide in engine. Chin. J. Mech. Eng.-En. 2002, 38, 96-101. [CrossRef]

17. Qi, L.; Zhao, L.; Ma, X.; Cui, H.; Zheng, W.; Lu, Y. Design and test of 3GY-1920 wide-swath type weeding-cultivating machine for paddy. Trans. Chin. Soc. Agric. Eng. 2017, 33, 47-55.

18. Rong, L.; Lunjun, C.; Ming, S.; Qi, Z.; Yong, L. Study on Friction and Wear Characteristics of Aluminum Alloy Hydraulic Valve Body and Its Antiwear Mechanism. Arch. Foundry Eng. 2017, 17, 207-215. [CrossRef]

19. Shein, I.R.; Medvedeva, N.I.; Ivanovskii, A.L. Electronic structure and magnetic properties of Fe3C with 3d and 4d impurities. Physica. Status. Solidi. B 2007, 244, 1971-1981. [CrossRef]

20. Medvedeva, N.I.; Kar Kina, L.E.; Ivanovskiľ, A.L. Effect of chromium on the electronic structure of the cementite Fe 3 C. Phys. Solid State 2006, 48, 15-19. [CrossRef]

21. Coronado, J.J. Abrasive size effect on friction coefficient of AISI 1045 steel and 6061-T6 aluminium alloy in two-body abrasive wear. Tribol. Lett. 60 2015, 40. [CrossRef]

22. Ghaffarian, H.; Taheri, A.K.; Ryu, S.; Kang, K. Nanoindentation study of cementite size and temperature effects in nanocomposite pearlite: A molecular dynamics simulation. Curr. Appl. Phys. 2016, 16, 1015-1025. [CrossRef]

23. Wong, T.; Kim, W.; Kwon, P. Experimental support for a model-based prediction of tool wear. Wear 2004, 257, 790-798. [CrossRef]

24. Sakai, M. Energy principle of the indentation-induced inelastic surface deformation and hardness of brittle materials. Acta Metall. Mater. 1993, 41, 1751-1758. [CrossRef]

25. Diomidis, N.; Mischler, S. Third body effects on friction and wear during fretting of steel contacts. Tribol. Int. 2010, 44, 1452-1460. [CrossRef]

26. Amiriyan, M.; Blais, C.; Savoie, S.; Schulz, R.; Gariépy, M.; Alamdari, H. Tribo-Mechanical Properties of $\mathrm{HVOF}$ Deposited $\mathrm{Fe}_{3} \mathrm{Al}$ Coatings Reinforced with $\mathrm{TiB}_{2}$ Particles for Wear-Resistant Applications. Materials 2016, 9, 117. [CrossRef]

27. Jiang, S.; Wang, H.; Wu, Y.; Liu, X.; Chen, H.; Yao, M.; Gault, B.; Ponge, D.; Raabe, D.; Hirata, A. Ultrastrong steel via minimal lattice misfit and high-density nanoprecipitation. Nature 2017, 544, 460-464. [CrossRef]

28. Masoumi, M.; Sinatora, A.; Goldenstein, H. Role of microstructure and crystallographic orientation in fatigue crack failure analysis of a heavy haul railway rail. Eng. Fail. Anal. 2019, 96, 320-329. [CrossRef] 
29. Xianglin, D. The effect of quench hardening on the fretting wear of medium carbon steel. Wear 1988, 123, 77-85. [CrossRef]

30. Zum Gahr, K.; Doane, D.V. Optimizing fracture toughness and abrasion resistance in white cast irons. Metall. Trans. A 1980, 11, 613-620. [CrossRef]

31. Sevim, I.; Eryurek, I.B. Effect of fracture toughness on abrasive wear resistance of steels. Mater. Des. 2006, 27, 911-919. [CrossRef]

32. Li, C.S.; Liu, X.H.; Wang, G.D.; Yang, G. Experimental investigation on thermal wear of high speed steel rolls in hot strip rolling. Mater. Sci. Technol. 2002, 18, 1581-1584. [CrossRef]

33. Zhao, M.; Huang, X.; Atrens, A. Role of second phase cementite and martensite particles on strength and strain hardening in a plain C-Mn steel. Mat. Sci. Eng. A. 2012, 549, 222-227. [CrossRef]

34. Lim, C.Y.H.; Lim, S.C.; Gupta, M. Wear behaviour of SiC p -reinforced magnesium matrix composites. Wear 2003, 255, 629-637. [CrossRef]

35. Chen, Y.; Huang, P. Experiment study on adhesion between rough surfaces. J. Tribol. 2016, 36, $269-275$.

36. Carey, J.P.; Craig, M.; Kerstein, R.B.; Radke, J. Determining a relationship between applied occlusal load and articulating paper mark area. The Open Dentistry J. 2007, 1, 1-7. [CrossRef]

37. Wen, S.; Huang, P. Principles of tribology; Wiley Online Library: Hoboken, NJ, USA, 2012.

38. Wang, S.Q.; Wei, M.X.; Wang, F.; Zhao, Y.T. Transition of elevated-temperature wear mechanisms and the oxidative delamination wear in hot-working die steels. Tribol. Int. 2010, 43, 577-584. [CrossRef]

39. Kalin, M.; Vižintin, J. High temperature phase transformations under fretting conditions. Wear 2001, 249, 171-181. [CrossRef]

40. Zhang, Y.S.; Han, Z.; Lu, K. Fretting wear behavior of nanocrystalline surface layer of copper under dry condition. Wear 2008, 265, 396-401. [CrossRef]

41. Zhang, N.; Zhang, J.; Lu, L.; Zhang, M.; Zeng, D.; Song, Q. Wear and friction behavior of austempered ductile iron as railway wheel material. Mater. Des. 2016, 89, 815-822. [CrossRef]

42. Chen, Y.K.; Han, L.; Chrysanthou, A.; O'Sullivan, J.M. Fretting wear in self-piercing riveted aluminium alloy sheet. Wear 2003, 255, 1463-1470. [CrossRef]

43. Berriche, Y.; Vallayer, J.; Trabelsi, R.; Treheux, D. Severe wear mechanisms in Al2O3-AlON ceramic composites. J. Eur. Ceram. Soc. 2000, 20, 1311-1318. [CrossRef]

44. Yun, J.Y.; Park, M.C.; Shin, G.S.; Heo, J.H.; Kim, D.I.; Kim, S.J. Effects of amplitude and frequency on the wear mode change of Inconel 690 SG tube mated with SUS 409. Wear 2014, 313, 83-88. [CrossRef]

45. Huang, X.; Neu, R.W. High-load fretting of Ti-6Al-4V interfaces in point contact. Wear 2008, 265, 971-978. [CrossRef]

46. Warmuth, A.R.; Shipway, P.H.; Sun, W. Fretting wear mapping: The influence of contact geometry and frequency on debris formation and ejection for a steel-on-steel pair. Proc. R. Soc. A 2015, 471, 471. [CrossRef] 